\title{
Walking Through, Going Along and Scrolling Back
}

\author{
Ephemeral mobilities in digital ethnography
}

\author{
Kristian Møller ${ }^{\mathrm{I}}$ \& Brady Robards ${ }^{\mathrm{II}}$ \\ I Digital Design, IT University of Copenhagen, Denmark, krimo@itu.dk \\ II School of Social Sciences, Monash University, Australia, brady.robards@monash.edu
}

\begin{abstract}
Spatial metaphors have long been part of the way we make sense of media. From early conceptualizations of the internet, we have come to understand digital media as spaces that support, deny or are subject to different mobilities. With the availability of GPS data, somatic bodily movement has enjoyed significant attention in media geography, but recently innovations in digital ethnographic methods have paid attention to other, more ephemeral ways of moving and being with social media. In this article, we consider three case studies in qualitative, "small data" social media research methods: the walkthrough, the go-along and the scroll back methods. Each is centred on observing navigational flows through app infrastructures, fingers hovering across device surfaces and scrolling-and-remembering practices in social media archives. We advocate an ethnography of ephemeral media mobilities and suggest that small data approaches should analytically integrate four dimensions of mediated mobility: bodies and affect, media objects and environments, memory and narrative, and the overall research encounter.
\end{abstract}

Keywords: small data, ethnography, social media, spatial turn, mobility

\section{Introduction}

Since the development and everyday adoption of the internet in the late 1980s and early 1990s, ethnographers have "gone digital": from connecting to research participants by email and web conferencing to using digital media as interventionist research tools in traditional field sites through to studying cultures that coalesce in digital social spaces. As with any emerging field, several influential delineations have been proposed over the years. Such contributions include Kozinets's (2009) work on "netnography", Hine's (2000) "virtual ethnography”, Boellstorff and colleagues (2012) "ethnography in virtual worlds" and more recently Pink and colleagues (2016) work on "digital ethnography". All of these accounts filtered understandings of media through the lenses of space, place and mobility. While the media material background has evolved and the

Møller, K. \& Robards, B. (2019). Walking through, going along and scrolling back: Ephemeral mobilities in digital ethnography. Nordicom Review, 40 (Special Issue 1): 95-109. doi:10.2478/ nor-2019-0016. 
analytical attention diverged, a fundamental ethnographic interest remains: how do we as researchers navigate digital cultures and produce rich, reflexive and polyphonic accounts of everyday life in mediatized society? To answer this question, we intend this article to act as 1) a conceptual working through of mobilities in contemporary digital "small data" ethnography at the same time as 2) a how-to guide for researchers aiming to study digital culture.

Recent digital ethnographic methodological innovations reflect general ontological and epistemological shifts within the field of internet research. In a digital media saturated world, the meaning of what constitutes presence and action is changing with the fast pace of development and adoption of socially mediating technologies. This also explains the continuous and ongoing efforts to describe an ethnography for mediatized society. In this article, we will focus on social media and draw out their aspects of everyday mobilities that, despite the increasing datafication, do not leave stable traces that can readily be observed. We believe that digital ethnography should serve as a counterpoint to the growing reliance on the found digital traces of big data sets, scraped and collected retrospectively. Here, we propose a methodological framework of "ephemeral, mediated mobilities" for representing less materialized ways of being with social media. The framework brings together small-scale media-body interactions - such as swipes and scrolls - that are often left unexplored due to them being between the intent of the user and a measurable action in the interface. The economic value of these small-scale interactions is also difficult to perceive. Our proposed framework is thus in other words concerned with somatic and digital movements, which, in our media ecology, remain largely untracked, unarchived or only precariously archived. Significantly, our framework places the user's action, experience and meaning making as central to productive research inquiry.

To flesh out what an ethnography of ephemeral mediated mobilities might attend to, we consider three methods as case studies. Each method was developed in response to social media that reconfigure sociality and intimacy in fundamental ways, namely hook-up apps and feed-based social media platforms. Compared with the chatrooms and virtual worlds studied in early "virtual ethnographic" work, these services have radically changed the way in which everyday closeness is produced and thus need fresh conceptualizations. Further, the long-term and sustained use of these technologies must now also be understood in longitudinal terms, as people and platforms begin to reflect (and capitalize) on years and years of social media histories (Robards, 2014).

To map out a broad range of ephemeral traces and determine how they can be pursued, we will explore three case studies: 1) the "walkthrough method" (Light et al., 2016) is an approach to mapping methodically how smartphone applications (apps) work; 2) the media go-along (Jørgensen, 2016) involves research participants giving a verbal and kinetic "guided tour" of an app, with the researcher intervening in different ways; and 3 ) the scroll back method (Robards \& Lincoln, 2017) entails working with research participants as co-analysts of longitudinal digital traces. The ephemeral traces pursued in these different yet related methods concern the mobilities of fingers moving across media device surfaces, of navigational flows through nested app infrastructures and of the different kinds of habitating, narrating and reflecting that digital social media allow. While these media mobilities might seem inconsequential, such easily forgotten ways of being with media should be accounted for, and we intend this article to support research endeavours and methodological interventions in this area of mediatized everyday life. 
Accordingly, first we explore the role of digital traces in media studies and argue that ethnography should put digital traces to work while remaining sensitive to what is not traced and made immediately visible. Then we will provide an overview of how spatial and mobile metaphors have been used in media studies, paying particular attention to the concepts of "mediated mobility" (Keightley \& Reading, 2014; Sheller, 2018) and "wayfaring" (Moores, 2014). Inspired by these, we suggest four dimensions along which ethnographers can construct the ephemeral aspects of mediated mobilities. We then apply this framework to the three case studies to show how they attend differently to ephemeral mediated mobilities. We conclude by suggesting future applications of the concept in digital media research as well as its limitations. In the following section, we explore the characteristics of a digital trace ethnography that takes advantage of the data left behind in current social communication infrastructures.

\section{Digital traces in ethnography}

The notion of persistent and archived-by-default digital traces has evolved over the last few years, with the introduction of more ephemeral digital traces. Snapchat was the first mainstream platform to allow users to send text, picture and video messages that would last only for a few seconds (or a 24-hour period in a "story"), vanishing shortly afterwards. Handyside and Ringrose (2017: 347) studied the role of Snapchat in mediating memory and intimacy among 18-year-olds and found that it offered a "temporal fastness and ephemerality" to their exchanges. At the same time, however, they also found examples of "fixity through the screenshotting of "disappearing' snaps" (Handyside \& Ringrose, 2017: 347), as users are able to bypass the intended temporary nature of a "snap" and record whatever was on their screen with their phone's screenshot function. This turn to the ephemeral was adopted later by Instagram and Facebook, through which users can create daily "stories" that tend to chronicle more mundane, everyday experiences that ostensibly disappear 24 hours later. It is now also possible to delete messages on Facebook, and to send images or videos on Instagram that are only accessible once.

Tracing or following is at the heart of ethnography, not least since the emergence of the multi-sited ethnographic paradigm (Marcus, 1995). Such ethnography constructs worlds through "movement and tracing within different settings of a complex cultural phenomenon" (ibid.: 106). In a mediatized society, digital traces of networked behaviour are plentiful, with social media presenting us with readily available material. In fact, social media platforms are in the business of trace making, or rather, trace selling. Features like the Facebook Timeline and Instagram's "your activity" dashboard offer up only a fraction of the insights produced in behind-the-scenes data analyses. Nevertheless, they offer media users a resource to think about their digital lives, which in turn creates a rich source for participant observation. Besides social media platforms, such ethnography may draw on the abundance of digital materials available in chat services, online forums or smartphone log data (Ørmen \& Thorhauge, 2015). The traces produced by most uses of social media are persistent and accrue over time through the archive-by-default modality of many of our digitally mediated interactions. They can be assembled or accessed and framed as rich texts for analysis by digital ethnographers. The characteristics that most social media share are a richness in digital traces that in Bowker's words has led to a "new regime of memory practices" (Bowker, 2007: 34). 
The concept of a "digital trace" has mostly been used to call attention to inscriptions in media that reflect human activity: the digital trace is digital traces are "records of activity [...] undertaken through an online information system" (Howison et al. 2011: 769). Hine noted that internet ethnography may engage with at least two types of traces: those readily available on social media platforms, for example, and those that the ethnographer forges through interventionist strategies to represent activity and make it available for collaborative interpretation (Hine, 2015). As digital traces are significant elements of the media spaces that people navigate daily, engaging with them in digital ethnography is the key to understanding what such media environments mean to their users. Further, in terms of media as social spaces, digital traces are the building blocks of what can be thought of as online presence and, thus, constitutive of a sense of online sociality. However, digital traces should not become the only thing that digital ethnographers follow. Digital ethnographers should, depending on the social object that they choose to follow, be able to integrate analyses of media objects and media environments reflexively, with traces of use, observation of participant media practice and media narration.

As sociological and critical internet studies are increasingly adopting the non-human-centric modes of analysis found in new materialism (Barad, 1996; Bennett, 2009; Van der Tuin \& Dolphijn, 2012), the reflexive foregrounding of mobile human bodies across static media backgrounds is being questioned. This perspective privileges encounters between different bodies that create marks in space that can then be interpreted to tell us stories of the encounter itself. In Ahmed's (2004) affective vocabulary, it is the "impression" left on one surface by another body that tells us about the mobilities with which the bodies came into contact, the marks that they left and the direction that they took after the "impact". Traces thus not only open up to the reading of past interactions and emotions but also imply their future directions or tendencies.

Further, non-human and new materialist approaches move past the typical ethnographic modus of reflexively interrogating the always already situated participant-researcher relationship, with media and other materials serving as the "field" backdrop, and instead grasp the research encounter as an assemblage acting on semiotic, material and social flows (Deleuze \& Guattari, 1988: 23). They emerge together in the research encounter, with both their individual characteristics and the "output" or momentum of the event/encounter becoming available to study. With many disparate sources of digital traces available, the work of "filling in the blanks" is not lessened but intensified:

Our capacity to join into others' attentional spaces, read intentions from minimal traces, attribute meaning and co-ordinate around presumed shared mental states, means that we are able to collaborate on the reduced fragments of data because we can fill in the gaps. (Broadbent \& Lobet-Maris, 2015: 117)

In other words, the place of digital traces in everyday lives cannot be extrapolated from a set of data points and, in ethnographic terms, the subject, thing or story (Marcus, 1995) cannot be followed through machine learning and algorithmic aggregation and visualization alone. Rather, it requires often-disparate elements across different temporal and spatial planes to be combined in ways that achieve internal structural cohesion by virtue of their internal relations and not by externally given logics.

To sum up, the ethnographic method in mediatized society should be able to follow ephemeral and fixed digital traces as well as creating its own traces, all of which should 
be integrated into the analysis of how everyday life with media looks and feels. While working actively with the agencies or directions of both people and media materials, and how they come together in the research encounter, we hold that ethnography should retain the human interest in critically approaching the ways in which everyday lives are touched by media. In the following, we draw from work on media space and mobility to approach the ways in which media "touch" everyday life through the concept of mediated mobility.

\section{From spatiality to mobility}

In media studies, spatial metaphors have long been employed to understand many aspects of mediatization (Harvey, 1989; Jenkins, 2010; Madianou \& Miller, 2013; McLuhan et al., 1968; Meyrowitz, 1998; Sandvik et al., 2016; Silverstone, 1994). In Life online: Researching real experience in virtual space (1998), Annette Markham explored how spatial metaphors allow for a reading of the internet and code as providing boundaries for presence and action, designs that designate certain entry and exit points. Here, while still focusing on media as stable frameworks, we see attention to the ways in which these frameworks shape the metaphorical movements that can be performed online. Similarly, others have pointed out that, when the field site spans multiple spaces to follow subjects and objects of interest around, social presence and participation must also become distributed and networked (Licoppe, 2015; Stempfhuber \& Liegl, 2016). Digital media have changed the repertoire of ethnographic practices in that recording and visualization technologies can be used to create new interventionist strategies that do not just follow but actively reconfigure participant-researcher knowledge production by introducing media objects into the research (Pink, 2007).

With the spatial turn in media studies, geography's influence on media studies was formalized. In anthologies on geographies of communication (Jansson \& Falkheimer, 2006) and media space (Couldry \& McCarthy, 2004), human and cultural geography have been used to describe the production of mediated space at different scales. With this turn, media studies became decidedly non-media-centric (Morley, 2008) by drawing together "imaginations, representations and (inter)subjective interpretations [...] implied or embedded in spatial practice and material structures" (Jansson, 2012: 143). Through this perspective on digital ethnography, we are able to shift our attention from the social interactions occurring in relation to a set of material structures towards the ways in which different digital materials are at once woven together in mobile practice and frame the kinds of mobility that are thinkable and doable. By centring on tensions of mobility and stillness, potentials and actualizations and the place-making efforts of both human and non-human actors, the paradigm is well suited to approaching the way in which digital trace ethnography can be performed. Specifically, the concept of mediated mobilities, the "interaction between an accumulation of spatially and temporally specific mediated political, economic, social and individual experiences [and] processes" (Keightley \& Reading, 2014: 297), is useful here. Ethnography of mediated mobilities should thus attend to the particular ways in which media and people are accumulated in certain encounters. Digital traces that are readily available as well as researcher- and participant-generated digital traces are central to the ways in which these accumulations are studied. 
To gain a more concrete understanding of what ephemeral mediated mobility looks like, Moores's reading of Ingold's “wayfaring” concept is useful (Ingold, 2011). Wayfaring describes practical engagement with lived-in environments as "alongly integrated inhabitant knowledge" (Moores, 2014: 201). From Moores's perspective, mediated mobility is "doubly digital" in that it involves both physical manipulations of media artefacts (such as finger to touchscreen) and imagined but just as real orientation and habitation in digital media environments, interfaces and affordances (ibid.: 204-205). Further, with the perspective of wayfaring in ethnographies of mediated mobility, narration and discourse are not conceived of as research "add-ons" that give different kinds of access but as types of "movement from place to place" (ibid.: 201). Knowledge of media environments is thus integrated into the ethnographic account at many levels. In this way, different ethnographic methods not only configure different paths with and through media environments but also different narrative paths to knowledge about mediatized life.

\section{Ethnographies of ephemeral mediated mobilities}

The question of mobility has also been approached from the perspective of emotions and affect. Sara Ahmed (2004) explored the power of emotions to move minds and bodies, making apparent the ways in which emotions attach to objects and how that serves to mobilize or pacify publics around different issues, sentiments and bodies. Conversely, Brian Massumi (2002) conceptualized the work of affect as a prediscursive force and bodies as multiple, both somatic and imagined. While the roles of affect and emotion are conceptualized differently, they both consider how contemporary culture operates in ways that require sense making that extends beyond practice, representation and discourse.

As mentioned in the previous section, another focus point in the literature has been the ways in which media frame sociality, experience and action. Generally, the spatial turn in media studies seeks to register the ways in which the layering and penetration of media things and services fundamentally shift what a social situation looks and feels like. Similarly, the intensified mediation of practice and the production of more stable, material traces have led to methodological innovations in the study of memory. Here, Kuhn's concept of "memory work" (2010) has been instrumental in the introduction of personal media materials into the study of everyday mediatized life. Memory work is performed by participants prompted by media into which lived life is somehow inscribed. Thus, it reflects the ephemeral and unstable nature of remembering in that it is inseparable from the surrounding material objects, which might change or even disappear over time.

Finally, with the vast amount of digital traces that are more or less readily available, what constitutes ethical research activity must be renegotiated. Such work is particularly pertinent to the field of internet studies, which has consequently responded with a number of collaboratively produced guidelines. The most recent iteration, from the Association of Internet Researchers (Markham et al., 2012) suggests that processual, situational, embodied and feminist ethics take the place of the application of a uniform ethical ideology and rule-based systems like those of ethical review boards. This response from the researcher community reflects the fact that, in complex mediatized 
social phenomena, "ethically important moments" (Guillemin \& Gillam, 2004) arise unexpectedly and that dealing with them is a messy process of unpacking the specific ways in which bodies and media come together in that moment.

Inspired by these works' attention to ephemeral and unstable relations, we suggest that ethnographies of mediated mobilities should observe and analytically integrate different dimensions of mobility, including:

1. Bodies and affect. How do media and their users somatically and semantically impress upon each other? What do these impressions tell us about the mediated circulation of identity and community ideals? How are their affective and agentic capacities actualized?

2. Media objects and environments. What mobile capacities of media are actualized in the ethnography? How are object attributes, interface affordances and media environmental genres mobilized?

3. Memory and narrative. What temporal distributions of mediated experience are traced? What memories and stories of media are mobilized and to what effect? What kinds of narrative on media structural change arise in ethnographic research encounters with media?

4. The research encounter. What elements are drawn together and how is agency distributed among them? With what directions and momentums do they enter into the encounter, what interactions and frictions occur during the encounter and what future directions can be speculatively constructed?

Now we consider three case studies that exemplify how ethnographic methods can attend to mediatized everyday life across these four dimensions of mediated mobility. The findings are summarized in Figure 1. We draw on two of our own independent research projects, and one other adjacent one, to develop three case studies of mediated mobilities in digital ethnography. First, we consider Light and colleagues (2016) study, which developed an approach to methodically mapping out how smartphone applications (apps) work - they called this the "walkthrough method". Second, we draw on Kristian Møller's (2017) study of gay men's mobile media use in Denmark, which involved research participants "walking through" app use with the researcher - he called this the "go-along method". Third and finally, we draw on the work of Brady Robards and Siân Lincoln (2017), which involved working with research participants as coanalysts of longitudinal digital traces on Facebook - they called this the "scroll back method". Taken together, these three case studies draw attention to the ways in which mobilities other than traversals of physical space can be observed and accounted for: walking, going and scrolling in digital spaces. The following case studies show how observing ephemeral mediated movements can produce rich, "small data", embedded and detailed ethnographic enquiries into digital cultures that extend beyond or rather "below" larger-scale methods. 
Figure 1. Four dimensions of mediated mobilities in the walkthrough, media go-along and scroll back methods

\begin{tabular}{|c|c|c|c|}
\hline \multirow[t]{2}{*}{$\begin{array}{l}\text { Dimensions of medi- } \\
\text { ated mobilities }\end{array}$} & \multicolumn{3}{|c|}{ Methods of digital ethnography } \\
\hline & Walkthrough & Media go-along & Scroll back \\
\hline Bodies and affect & Navigational flow & Navigational style & $\begin{array}{l}\text { Archived semantic } \\
\text { bodies and iden- } \\
\text { tities }\end{array}$ \\
\hline $\begin{array}{l}\text { Media objects and } \\
\text { environments }\end{array}$ & Expected use & $\begin{array}{l}\text { Structuring invita- } \\
\text { tions for go-alongs }\end{array}$ & $\begin{array}{l}\text { Algorithmic resurfa- } \\
\text { cing of history }\end{array}$ \\
\hline $\begin{array}{l}\text { Memory and } \\
\text { narrative }\end{array}$ & $\begin{array}{l}\text { Researcher media litera- } \\
\text { cies guide the narration }\end{array}$ & $\begin{array}{l}\text { Haptic and seman- } \\
\text { tic wayfaring }\end{array}$ & $\begin{array}{l}\text { Personal and inter- } \\
\text { face biography }\end{array}$ \\
\hline $\begin{array}{l}\text { Ethics of the research } \\
\text { encounter }\end{array}$ & $\begin{array}{l}\text { Researcher carefully } \\
\text { evaluating assumptions } \\
\text { of privacy }\end{array}$ & $\begin{array}{l}\text { Distributed ethical } \\
\text { agency in medi- } \\
\text { ated access and } \\
\text { narration }\end{array}$ & $\begin{array}{l}\text { Distributed ethical } \\
\text { agency in mediated } \\
\text { access and nar- } \\
\text { ration }\end{array}$ \\
\hline
\end{tabular}

\section{The walkthrough method: Preferred mobilities of the interface}

Social activity increasingly occurs within apps, which in an ethnographic sense operate as cultural scenes in which certain actions are valorized while others are made impossible. The walkthrough method developed by Light and colleagues (2016) works to map out these app surfaces, methodically moving through an app's design and functionality to identify discrete affordances. In using the walkthrough method, the researcher moves across the media landscape, noting both the physical manipulations of the smartphone, tablet or computer and the preferred uses and mobilities indicated in the media environmental interface. By "participating" in the implied flows of practice while analysing how these surfaces are culturally coded and meaningful, the walkthrough method allows the researcher to observe how different apps structure presence and action. This method aims to understand what seemingly mundane apps do and feel like. The apps are "made strange" by moving slowly through them, applying analytical categorization to every design element, allowing a detailed analysis of how entry and exit point architecture shapes the flow of arrival and departure.

The walkthrough method captures how the researcher navigates through the interface. The method affords the researcher high mobility in that he or she can access every corner of the media interface, taking time to reflect on how it feels to inhabit each of these areas. As a sense of habitation arises from pre-established knowledge and impressions as well as in direct engagement with the material space at hand, the field notes detail narratives of the sequences of interface affordances with the social coding that the researcher reads into each button, layout, profile picture and so on. The reading of the interface is thus narratively entangled with the embodied knowledge that the researcher enters with and the sequential flow through which his or her body walks through and explores the app.

The app as a material environment is subjected to readings of what is considered to be "expected use", that is, ways of using the interface that are materially coded into the app. The researcher approaches the app with existing knowledge of app design. The researcher may also be familiar with the "genre" of apps into which the app of interest 
falls: dating/hook-up apps, image sharing, instant messaging, games and so on. Each genre has its own pre-existing norms and conventions that users might expect to find in similar apps. This knowledge shapes the researcher's approach and determines a set of expectations. Light and colleagues (2016) explained that apps also operate within an environment of "expected use": "how [the] app provider anticipates it will be received, generate profit or other forms of benefit and regulate user activity" (Light et al., 2016: 3 ). The method thus acknowledges both the multiplicity of reading strategies to which apps are subject and the fact that users will typically read the interface similarly and follow similar pathways.

By foregrounding the assemblage performed by the researcher, the researcher literacies relating to the media genre and the communities organized within them become central factors in understanding how the app cultures are narratively constructed in academic writing. As such, the method somewhat backgrounds the possibility of a multiplicity of voices in the narration of user-and-interface cultures that other more person- and identity-focused methods might produce.

Ethically, applying the walkthrough method to the study of apps requires the researcher to pay particular attention to the ways in which he or she becomes visible to other users, how such a presence might be perceived, how such a presence might negatively affect the users' sense of pleasure and safety and what kinds of risks the researcher might face. Because the method foregrounds the media and cultural literacies of the researcher, they can be put to work in the careful description of navigating the app. Knowledge about and in relation to the mediatized cultures of the app is thus foregrounded and choices regarding avoiding and disseminating risks are filtered through this lens. Thus, the researcher is well positioned to choose carefully a representation strategy that takes into consideration the relationship between the cultural make-up of the scene and the researcher's personal and academic positions. At the same time, by being the only participant, the reflective potential in engaging with other ways of wayfaring and inhabiting the media is foregone. While textual bodies (in profile texts and chat messages) could be engaged with in such reflective matter, they are mostly backgrounded too, treated as ethical liabilities in the sense that they to a certain degree are taking part in research unknowingly.

\section{The media go-along method: Collaborative orientation and mobility}

Whereas the walkthrough method centres on the researcher's experience of an app, the media go-along method (Jørgensen, 2016) combines interview and participant observation to understand how participants use personal mobile media. Concretely, the researcher interviews and observes the participant while he or she uses his or her own device and social media service accounts. The method identifies three media environmental aspects for which observation and narration can operate: affordances, representations and communications. The method is highly collaborative, as the intervention offers both the researcher a resource for asking relevant questions and the participants the ability to take control of their memory work (Kuhn, 2010). While it allows for the description of expected mobilities embedded in interfaces, something on which the walkthrough method focuses, it is more attuned to the uptake of these and what that tells us about the media user and his or her place in the mediated community. 
With the method, the researcher is able to tell stories of bodily mobilities across interfaces, of how people are with their media and of their sense of ease, joy, disorientation or estrangement. By observing the somatic mobilities of limbs touching interfaces, it enables the researcher to approach an understanding of the different purposes and styles of wayfaring, that is, somatic clues to the participant's position in and affective relationship to the mediated culture at hand. Such narratives can, for example, highlight the temporal instability of body-media relationships, because they capture sequences of user-interface interaction and narrations that might show disparate and directionchanging ways of inhabiting personal media technologies. In other words, the method allows nuanced bodily relationships to media to emerge in research accounts, challenging the stable categories of "user types".

The media go-along method produces narratives of collaborative haptic and semantic wayfaring across the smartphone interface and environment and foregrounds how these narratives are negotiated between researcher and participant. By combining field notes on behaviour and audio recordings of discourse, it creates the basis for analytically integrating narration as it arises in tandem with somatic wayfarings across the smartphone screen and environment, scrolling up and down and pressing buttons to move through different sections of the services. Such mediated memory work might arise from engaging with either the interface structural parts and what they signify or the representational culture present in user profile pictures and texts or in communicative histories of the chat message archive.

When privacy online is framed as a question of contextual integrity, formal procedures for informed consent do not suffice. Here, the media go-along research encounter brings to the foreground the practical ethics of gaining visual and narrative access through encounters with personal social media. As this access extends to third parties in the sense that their private messages become visible and commented on, it is relevant to ask what ethical implications such intimate observation has and what risk dissemination strategies should be applied accordingly. The method suggests that practice-based ethics could usefully be conceived of as the careful negotiation of mobilities. With the media go-along method's attention to the temporal instability of interface interactions, the researcher should be ready to pay special attention to how the encounter has unfolded to arrive at an ethically fraught moment and to consider who is present in the moment and what should be undertaken next to de-escalate it. Third parties are by far the most immobile in that they are not able to tell that their digital representations and interactional traces are visible to the researcher. An ethics of care would require the researcher to be extra cautious around such textual bodies. Conversely, as the participants control the media device, they are able to go wherever they want in the interface and furthermore, with a flick of the wrist, deny the researcher visible access. Somewhat complicating this sense of unrestricted mobility, it should be noted that the researcher typically holds a privileged and revered position in the situation and is able to turn that into powerful "suggestions" or "invitations" regarding where the participant should go next. Thus, the method is well positioned to inform digital practical judgement through rich contextual, reflected and negotiated research moments but also to allow the researcher to consider and activate distributed ethical agency in his or her ethical navigation. 


\section{The scroll back method: Mobility of memory}

The scroll back method (Robards \& Lincoln, 2017) was designed to study how social media disclosure practices change over time and to work with research participants to reflect on the longitudinal nature of digital traces on social media. Whereas the walkthrough and go-along methods are focused on the here and now (for the researcher in the former and the participant in the latter), the scroll back method attends more closely to historical digital traces and to capturing change over time. The scroll back method involves sitting with research participants as they scroll back through their social media timelines or profiles and asking them to narrate and explain what they see. The method mobilizes digital traces recorded and marked as significant by either the Facebook user or the Facebook algorithm (through likes, comments and so on). The memory work in the method relates to user- and machine-produced significance markers. The research attention paid to this relies on the degree to which the participant is able to reflect on the reworking of recorded moments. In this way, the scroll back method uses the Facebook timeline as a memory object and, through collaborative interrogation of it, confronts the participant with earlier versions of his or her mediatized life through memory objects. Thus, the scroll back interview involves revisiting the archived "semantic bodies" of research participants, often producing experiences of nostalgia, embarrassment, shame and joy (Robards \& Lincoln, 2017). It should be noted that, while the method was developed for Facebook in particular, as it was the most long-standing, still widely used platform at the time, it can be adapted and applied to any form of social media in which there is a persistent record of posts, images and other disclosures.

The method foregrounds the dynamic aspects of media, more specifically how algorithms work to resurface and reassemble a personal user history into narratives. Chronological records of posts and tags are a main component of contemporary social media platforms, most prominently exemplified by Facebook's "Timeline". While these are presented as rather static and temporally organized life narrative archives, they should more accurately be described as a representation of user inputs, which have been produced within a digital framework subject to both incremental changes and major redesigns. An example of one such change is the ways in which Facebook presents the user with "friendship stories" or "this day x years ago". These are de- and re-contextualization's of user inputs, blurring the line between human and algorithmically generated memory objects.

While scrolling back through memory texts offers a chance to obtain rich narratives of mediatized life, it also heightens the risk of unearthing information that the participant did not anticipate, which may be uncomfortable or even problematic to share with a researcher. Like the go-along method, the scroll back method is necessarily intimate in many ways, as the digital traces that are produced through the use of digital media are traces of personal and intimate lives: sleeping patterns, friendships, familial ties, tastes and interests, sex lives and experiences of loss, sadness and elation. In a research scenario, the "contextual integrity" (Nissenbaum, 2004) of certain disclosures can become compromised. The ethical practice around this method should apply strategies to limit the risk of such unwanted affective intensities arising and be ready for when they do. One question that the researcher should ask of him-/herself and the participant is whether the participant is aware of such a risk, how precarious and marginal their lives are and to what degree they are able to deal with what might be remembered. Thus, ethical conduct 
becomes a question of the degree to which the ethical agency can be distributed or, in other words, whether it is sustainable to rely on the participant's judgement.

\section{Conclusion}

In this article, we have considered three case studies along four dimensions of mediated mobilities. The walkthrough reflexively observes navigational flows through nested app infrastructures, the media go-along interprets how fingers hover over and make traces across media device surfaces and the scroll back method explores collaborative scrolling-and-remembering practices in social media archives.

These research methods overlap and complement each other in different ways. While the walkthrough method and the go-along method are centred on the user's experience of an app in the here and now, the scroll back method is more concerned with the historical digital traces, collected over years of social media use. Whereas the walkthrough method is focused on the experience of the researcher, navigating the app and its interface, the go-along and scroll back methods attend to the experiences of research participants as users of apps and social media. These everyday experiences are often intimate and deeply personal, requiring careful and sensitive negotiations. In some scenarios, a combination of the methods across the stages of a research project could be useful: walking through digital space as a researcher initially, going along with research participants to learn how they use the app or media and scrolling back with research participants to uncover their historical uses.

Together they contribute to the geographical strain in media studies by carving out an ethnography of ephemeral mediated mobilities that makes visible aspects of everyday media that might otherwise pass unnoticed in research focusing on larger-scale media mobility. More specifically, they offer a framework for integrating spatial and temporal analyses of human-and-media interactions: spatially, how orientations and actions arise or are redirected or even unmade in relation to encounters with media infrastructures and, temporally, how histories of media and people shape the direction, speed and force with which they enter the observed research encounter. Further, by carefully constructing a situational analysis of media-user encounters, they effectively operationalize the calls for practice-based and affectively oriented ethics in internet research (Ess \& the AoIR Ethics Working Committee, 2002; Markham et al., 2012). Concretely attending to mobilities that leave ephemeral traces is hard or impossible within many existing ethnographic frameworks. Because the physical mobilities that operate on such a small scale cannot be captured and represented with GPS positioning technology, log data approaches cannot fully attend to this. Other methods must then be used to make visible the orientations and mobilities of bodies and limbs towards media interfaces, revealing more aspects of users' everyday life than their onscreen traces imply. Thus, following these ephemeral traces allows us to learn about the phenomenological aspects of being with media that might otherwise remain out of sight. Further, by attending to the four dimensions of mobility, the intimate relationship between infrastructural affordances and human thought and memory is centred. This is achieved not by privileging human cognition and narration as the only sites on which biography and meaning are produced but by having this arise in complex intra-actions with ever-changing landscapes of coded technologies and social media surfaces. 
We suggest that, in practice, following ephemeral traces typically means substituting or merging methods like those examined in this article into typical tools for media ethnography alongside researcher fieldnotes, participant diaries and ethnographic interviews. Introducing such interventions will in practice mean that the interview process slows down, making a wider array of experiences strange and thus more readily representable. In written discourse, it similarly requires the researcher and participant to reflect on more dimensions of their practices, motivations and emotions. In contrast, media ethnography based on Kozinets's (2009) netnography or similar online-only observational methods is less attuned to the study of ephemeral traces, simply because the participants' somatic engagements are not considered.

This article has drawn on methods developed to gain a better understanding of everyday life with dating/hook-up apps and feed-based social media. However, we believe that the study of any interactive media technology that is part of everyday life could benefit from attending to those mobilities of use, of action and of thinking that are not readily available. Fields in which this approach could be useful include not only media and internet studies but also human-computer interaction, design, social geography and cultural studies.

Finally, there is the question of the assumed subject of study. Digital ethnographic interventions that pay attention to the four dimensions' mediated mobilities will require them to be comfortable with very intense encounters. What, then, might such an intense encounter obscure? Which subjects are able to navigate sustainably such an intense intimacy with the researcher, with the media objects and with their memories? It seems that the pure versions of these methods are geared to highly reflexive subjectivities without trauma or social anxiety who are comfortable with sharing deeply personal narratives from their media use. In other words, the methods might require acts in which non-normative and precarious subjects might not feasibly engage. As such, we suggest that further attention should be given to the intersectional aspects of studying ephemeral mediated mobilities.

\section{References}

Ahmed, S. (2004). The cultural politics of emotion. London \& New York: Routledge.

Barad, K. (1996) Meeting the universe halfway: Realism and social constructivism without contradiction. In L. H. Nelson \& J. Nelson (eds.), Feminism, science, and the philosophy of science. Synthese Library, vol. 256. Springer: Dordrecht.

Bennett, J. (2009). Vibrant matter: A political ecology of things. Durham: Duke University Press.

Bowker, G. C. (2007). The past and the Internet. In J. Karaganis (ed.) Structures of participation in digital culture (pp. 20-36). New York: Social Science Research Council.

Boellstorff, T., Nardi, B., Pearce, C. \& Taylor, T. L. (2012). Ethnography and virtual worlds: A handbook of method. Princeton: Princeton University Press.

Broadbent, S. \& Lobet-Maris, C. (2015). Towards a grey ecology. In L. Floridi (ed.), The onlife manifesto (pp. 111-124). New York: Springer Open.

Couldry, N. \& McCarthy, A. (eds.). (2004). Media space: Place, scale and culture in a media age. London \& New York: Routledge.

Deleuze, G. \& Guattari, F (1988). A thousand plateaus: Capitalism and schizophrenia. London: Bloomsbury Publishing.

Ess, C. \& the AoIR Ethics Working Committee (2002). Ethical decision-making and Internet research: Recommendations from the AoIR Ethics Working Committee. Retrieved from https://aoir.org/reports/ethics. pdf [accessed 2018, April 8].

Guillemin, M. \& Gillam, L. (2004). Ethics, reflexivity, and “ethically important moments" in research. Qualitative Inquiry, 10(2): 261-280. 
Handyside, S. \& Ringrose, J. (2017). Snapchat memory and youth digital sexual cultures: Mediated temporality, duration and affect. Journal of Gender Studies, 36(4): 347-360.

Harvey, D. (1989). The condition of postmodernity. Oxford: Blackwell.

Hine, C. (2000). Virtual ethnography. Thousand Oaks, SAGE.

Hine, C. (2015). Ethnography for the internet: Embedded, embodied and everyday. London: Bloomsbury Publishing.

Howison, J., Wiggins, A. \& Crowston, K. (2011). Validity issues in the use of social network analysis with digital trace data. Journal of the Association for Information Systems, 12(12): 767-797.

Ihde, D. (1995). Postphenomenology. Northwestern University Press.

Ingold, T. (2011). Being alive: Essays on movement, knowledge and description. London \& New York: Routledge.

Jansson, A. (2012). A second birth? Cosmopolitan media ethnography and Bourdieu's reflexive sociology. International Journal of Cultural Studies, 16(2): 135-150.

Jansson, A. \& Falkheimer, J. (eds.) (2006). Geographies of communication: The spatial turn in media studies. Gothenburg: Nordicom.

Jenkins, H. (2010). Transmedia storytelling and entertainment: An annotated syllabus. Continuum, 24(6): 943-958.

Jørgensen, K. M. (2016). The media go-along: Researching mobilities with media at hand. MedieKultur. Journal of Media and Communication Research, 32(60): 32-49. Retrieved from http://ojs.statsbiblioteket.dk/ index.php/mediekultur/article/view/22429/20840. [Accessed 2018, March 20].

Keightley, E. \& Reading, A. (2014). Mediated mobilities. Media, Culture \& Society, 36(3): 285-301.

Kozinets, R. (2010). Netnography: Doing ethnographic research online. London: SAGE.

Kuhn, A. (2010). Memory texts and memory work: Performances of memory in and with visual media. Memory Studies, 3(4): 298-313.

Licoppe, C. (2015). Contested norms of presence. In K. Hahn \& M. Stempfhuber (eds.), Präsenzen 2.0 (pp. 97-112). New York: Springer.

Light, B., Burgess, J. \& Duguay, S. (2016). The walkthrough method: An approach to the study of apps. New Media \& Society, 1-20.

Madianou, M. \& Miller, D. (2013). Polymedia: Towards a new theory of digital media in interpersonal communication. International Journal of Cultural Studies, 16(2): 169-187.

Marcus, G. E. (1995). Ethnography in/of the world system: The emergence of multi-sited ethnography. Annual Review of Anthropology, 24: 95-117.

Markham, A. (1998). Life online: Researching real experience in virtual space. Lanham: Rowman Altamira.

Markham, A., Buchanan, E. \& the AoIR Ethics Working Committee. (2012). Recommendations from the AoIR Ethics Working Committee (Version 2.0) (p. 19).

Massumi, B. (2002). Parables for the virtual: Movement, affect, sensation. Duke University Press.

McLuhan, M., Fiore, Q. \& Agel, J. (1968). War and peace in the global village. New York: Bantam Books.

Meyrowitz, J. (1998). Multiple media literacies. Journal of Communication, 48(1): 96-108.

Moores, S. (2014). Digital orientations: "Ways of the hand" and practical knowing in media uses and other manual activities. Mobile Media \& Communication, 2(2): 196-208.

Morley, D. (2008). For a materialist, non-media-centric media studies. Television \& New Media, 10(1): $114-116$

Møller, K. (2017). The mediatization of intimacy: A study of hook-up apps and gay men's intimacy cultures. Ph.D. dissertation. Institute for the Study of Culture, University of Southern Denmark.

Nissenbaum, H. (2004). Privacy as contextual integrity. Washington Law Review, 101-139.

Ørmen, J. \& Thorhauge, A. M. (2015). Smartphone log data in a qualitative perspective. Mobile Media \& Communication, 3(3): 335-350.

Pink, S. (2007). Walking with video. Visual Studies, 22(3): 240-252.

Pink, S., Horst, H., Postill, J., Hjorth, L., Lewis, T. \& Tacchi, J. (2016). Digital ethnography. Springer.

Robards, B. (2014). Mediating experiences of "growing up" on Facebook's Timeline: Privacy, ephemerality and the reflexive project of self. In A. Bennett \& B. Robards (eds.) Mediated youth cultures (pp. 26-41). London: Palgrave Macmillan.

Robards, B. \& Lincoln, S. (2017). Uncovering longitudinal life narratives: Scrolling back on Facebook. Qualitative Research, 17(6): 715-730.

Sandvik, K., Thorhauge, A. M. \& Valtysson, B. (2016). The media and the mundane: Communication across media in everyday life. Gothenburg: Nordicom.

Sheller, M. (2018). Media, materiality, mobility: Understanding geomedia as infrastructure spaces. In K. Fast, A. Jansson, J. Lindell, L. R. Bengtsson \& M. Tesfahuney (eds.), Geomedia studies (pp. 79-94). London \& New York: Routledge.

Silverstone, R. (1994). Television and everyday life. London \& New York: Routledge. 
Walking Through, Going Along and Scrolling Back

Stempfhuber, M. \& Liegl, M. (2016). Intimacy mobilized: Hook-up practices in the location-based social network Grindr. Österreichische Zeitschrift Für Soziologie, 41(1): 51-70.

Urry, J. \& Büscher, M. (2009). Mobile methods and the empirical. European Journal of Social Theory, 12(1): 99-116.

Van der Tuin, I. \& Dolphijn, R. (2012). New materialism: Interviews \& cartographies. Open Humanities Press. 